\section{Beers Criteria versus Screening Tool of Older Persons' Potentially Inappropriate Prescriptions in evaluation of drug-prescribing practice in an Indian hospital}

\author{
Dominic Benjamin ${ }^{1}$, MRCP(Geriatrics), CCT(Geriatrics), FRCP(Lon), Manisha \\ Thankachan², Dip Clinical Pharm, R Saranya ${ }^{2}$ Dip Clinical Pharm
}

\begin{abstract}
Purpose. To compare the Beers Criteria and Screening Tool of Older Persons' Potentially Inappropriate Prescriptions (STOPP) in identifying potentially inappropriate medication (PIM) and adverse drug reaction (ADR) among Indian geriatric inpatients.

Methods. Patients aged $\geq 60$ years who were admitted to the geriatric medicine ward of Bangalore Baptist Hospital between January 2016 and July 2016 were observed throughout the hospital stay. Medical records of patients were reviewed to determine PIM and ADR. The Beers Criteria and STOPP were used to identify PIM.
\end{abstract}

Results. 226 male and 124 female geriatric patients aged 60 to 92 (median, 68) years were included. The median number of medications was 12 (range, 0-26), the median number of comorbidities was 2 (range, 1-6), and the median length of hospital stay was 5 (range, 1-23) days. Respectively for the Beers Criteria and STOPP, 97 (27.7\%) and 86 $(24.6 \%)$ patients were identified to have $136(38.9 \%)$ and 108 (30.9\%) PIMs and 11 (3.1\%) and 7 (2.0\%) ADRs. Beers Criteria was more likely to identify PIM than STOPP (0.2 vs. 0.1 per patient, $\left.\chi^{2}=43.21, \mathrm{p}<0.001\right)$. The Beers Criteria was more sensitive ( 0.59 vs. 0.52$)$ but less specific (0.60 vs. 0.65 ) than STOPP in identifying PIMs.

Conclusion. The Beers Criteria was more sensitive but less specific than STOPP in identifying PIMs. The prevalence of PIMs was high among elderly patients in our geriatric medicine ward. The use of the Beers Criteria or STOPP may help reduce PIM and ADR.

Key words: Aged; Drug-related side effects and adverse reactions; Potentially inappropriate medication list

\section{ORIGINAL ARTICLE}

\author{
Department of Geriatric Medicine, \\ Bangalore Baptist Hospital, Bangalore, \\ India \\ 2 Department of Pharmacy Practice, \\ Karnataka College of Pharmacy, \\ Bangalore, India
}

Correspondence to: Dominic Benjamin, Department of Geriatric Medicine, Bangalore Baptist Hospital, Bangalore, India. Email: dominicbenjamin25@gmail.com

\section{INTRODUCTION}

Potentially inappropriate medication (PIM) is a major health care concern in elderly patients. It increases the risk of adverse drug reaction (ADR), drug-drug interaction, hospital admission, and health care cost. Among hospitalised patients, ADR is the fifth most common cause of death. ${ }^{1}$ Ageing results in changes in pharmacodynamics that alter body sensitivity to different classes of drugs (anticoagulants, psychotropic, and cardiovascular) and pharmacokinetics that prolong elimination halflife owing to reduced renal and hepatic clearance and increased volume distribution of lipid soluble drugs. ${ }^{2}$ 
PIM is assumed when the adverse effect outweighs the clinical outcome and a more effective and safer therapy is available for the same problem..$^{3-5}$ There are various criteria to identify PIM in elderly patients. ${ }^{6}$ Although the Beers Criteria are commonly used in large-scale epidemiological studies, some of the Beers Criteria are controversial and almost half of PIMs in the Beers Criteria are unavailable in European formularies. ${ }^{78}$ The Screening Tool of Older Persons' Potentially Inappropriate Prescriptions (STOPP) and the Screening Tool to Alert Doctors to Right Treatment (START) are evidence-based criteria. The STOPP comprises 65 criteria to systematically identify PIMs.

India's geriatric population is expected to increase from $8.3 \%$ to $10.7 \%$ by $2021 .^{9}$ This study aimed to compare the Beers Criteria and STOPP in identifying PIM and ADR among Indian geriatric inpatients. This may help health care professionals to make drug-prescribing decisions according to risk-benefit assessment. ${ }^{10}$

\section{METHODS}

This prospective study was approved by the ethics committee of the Bangalore Baptist Hospital and conducted in compliance with the Declaration of Helsinki. Informed consent was obtained from each patient. Patients aged $\geq 60$ years who were admitted to the geriatric medicine ward of Bangalore Baptist Hospital between January 2016 and July 2016 were observed throughout the hospital stay. Patients presenting to the outpatient, gynaecology, chemotherapy, or emergency department were excluded due to difficulty in follow-up.

Medical records of patients were reviewed to determine PIM and ADR. The Beers Criteria and STOPP were used to identify PIM. Causality of the ADR was assessed using the Naranjo algorithm ${ }^{11}$ and World Health Organization Adverse Drug Reaction Probability Scale. ${ }^{12}$ Severity of ADR was assessed using the Modified Hartwig and Siegel Scale. Causality, severity, and preventability of ADR were re-checked by a senior geriatric consultant.

Continuous variables of the Beers Criteria and STOPP were compared using the Mann-Whitney $U$ test. The number of patients with PIM was the endpoint for assessment of sensitivity and specificity, using a $2 \times 2$ contingency table. Predictors of PIM were identified in the bivariate analysis using the Pearson Chi-squared test. Variables assessed in the bivariate analysis were age, number of comorbidities, number of medications, and length of hospital stay. A multivariate logistic regression model was used to evaluate the influence of predictors on PIM. A $p$ value of $<0.05$ was considered statistically significant.

\section{RESULTS}

226 male and 124 female geriatric patients aged 60 to 92 (median, 68) years were included. The median number of medications was 12 (range, 0-26), the median number of comorbidities was 2 (range, 1-6), and the median length of hospital stay was 5 (range, 1-23) days (TABLE $\mathbf{1}$ ).

Respectively for the Beers Criteria and STOPP, 97 $(27.7 \%)$ and $86(24.6 \%)$ patients were identified to have 136 (38.9\%) and 108 (30.9\%) PIMs caused by 18 and 8 medications and $11(3.1 \%)$ and 7 (2.0\%) ADRs caused by 7 and 5 medications (TABLE 2). Of a total of 13 ADRs, 4 were identified by both the Beers Criteria and STOPP: gastrointestinal ulcer caused by aspirin $(n=2)$, dry mouth caused by chlorpheniramine maleate $(n=1)$, and confusion caused by promethazine $(n=1)$. The Beers Criteria identified 7 additional ADRs: confusion or constipation caused by amitriptyline $(n=4)$, hyperkalaemia caused by spironolactone $(n=1)$, constipation caused by hydroxyzine hydrochloride $(n=1)$, and orthostatic hypertension caused by prazosin $(n=1)$. The STOPP identified 3 additional ADRs: hyperglycaemia caused by hydrocortisone $(n=2)$ and hyponatraemia caused by sertraline $(n=1)$.

Among patients with PIM, the Beers Criteria and STOPP were comparable in the percentage of male and female patients $(58.8 \%$ male vs. $62.8 \%$ female, $\left.\chi^{2}=0.31, p=0.575\right)$, the age of patients $(70$ vs. 68 years, Mann-Whitney $Z=0.095, p=0.928)$, the number of medications (12 vs. 12, Mann-Whitney $\mathrm{Z}=-0.09864, \mathrm{p}=0.92)$, the number of comorbidities ( 2 vs. 2 , Mann-Whitney $Z=0.60, p=0.5485$ ), and the length of hospital stay ( 6 vs. 6 days, Mann-Whitney $\mathrm{Z}=-0.1771, \mathrm{p}=0.8572)$.

The Beers Criteria was more likely to identify PIMs than STOPP (0.2 [0-3] vs. 0.1 [0-2] per patient, 
TABLE 1

Characteristics of patients with potentially inappropriate medication (PIM)

\begin{tabular}{|c|c|c|c|c|c|}
\hline \multirow[t]{2}{*}{ Characteristics } & \multirow[t]{2}{*}{$\begin{array}{c}\text { No. }(\%) \text { of } \\
\text { patients }(n=350)\end{array}$} & \multicolumn{2}{|c|}{ Beers Criteria } & \multicolumn{2}{|c|}{$\begin{array}{c}\text { Screening Tool of Older Persons' } \\
\text { Potentially Inappropriate } \\
\text { Prescriptions }\end{array}$} \\
\hline & & No. of PIMs & $\begin{array}{l}\text { No. (\%) patients } \\
\text { with PIM }\end{array}$ & No. of PIMs & $\begin{array}{l}\text { No. (\%) patients } \\
\text { with PIM }\end{array}$ \\
\hline \multicolumn{6}{|l|}{ Sex } \\
\hline Male & $226(64.6)$ & 80 & $57(25.2)$ & 69 & $54(23.9)$ \\
\hline Female & $124(35.4)$ & 56 & $40(32.3)$ & 39 & $32(31.5)$ \\
\hline \multicolumn{6}{|l|}{ Age (years) } \\
\hline $60-64$ & $100(28.6)$ & 41 & $27(27.0)$ & 35 & $26(26.0)$ \\
\hline $65-69$ & 93 (26.6) & 29 & $21(22.6)$ & 23 & $19(20.4)$ \\
\hline $70-74$ & $67(19.1)$ & 24 & 18 (26.9) & 15 & $14(20.9)$ \\
\hline $75-79$ & $47(13.4)$ & 18 & 15 (31.9) & 13 & $11(23.4)$ \\
\hline$\geq 80$ & $43(12.3)$ & 24 & $16(37.2)$ & 22 & $16(37.2)$ \\
\hline \multicolumn{6}{|c|}{ No. of comorbidities } \\
\hline 1 & $162(46.3)$ & 65 & $42(25.9)$ & 51 & $41(25.3)$ \\
\hline 2 & 103 (29.4) & 31 & $25(24.3)$ & 24 & $20(19.4)$ \\
\hline 3 & $49(14.0)$ & 26 & $18(36.7)$ & 22 & $17(34.7)$ \\
\hline$\geq 4$ & $36(10.3)$ & 14 & 12 (33.3) & 11 & $8(22.2)$ \\
\hline \multicolumn{6}{|c|}{ No. of medications during hospital stay } \\
\hline $1-4$ & $15(4.3)$ & 2 & $2(13.3)$ & 2 & $2(13.3)$ \\
\hline $5-9$ & $130(37.1)$ & 33 & 25 (19.2) & 26 & $22(16.9)$ \\
\hline $10-14$ & $132(37.7)$ & 55 & $38(28.8)$ & 44 & $34(25.8)$ \\
\hline 15 & 73 (20.9) & 46 & $32(43.8)$ & 36 & $28(38.4)$ \\
\hline \multicolumn{6}{|c|}{ Length of hospital stay (days) } \\
\hline $1-4$ & $132(37.7)$ & 43 & $32(24.2)$ & 32 & $26(19.7)$ \\
\hline $5-9$ & $177(50.6)$ & 73 & $50(28.3)$ & 61 & $49(34.5)$ \\
\hline $10-14$ & $25(7.1)$ & 14 & $10(40.0)$ & 11 & $7(28.0)$ \\
\hline$\geq 15$ & $16(4.6)$ & 6 & $5(31.3)$ & 4 & $4(25.0)$ \\
\hline
\end{tabular}

$\left.\chi^{2}=43.21, \mathrm{p}<0.001\right)$. The Beers Criteria was more sensitive $(0.59$ [ $95 \%$ confidence interval $(\mathrm{CI})=0.50$ $0.67]$ vs. $0.52[95 \% \mathrm{CI}=0.42-0.62])$ but less specific (0.60 [95\% CI=0.55-0.64] vs. 0.65 [95\% CI=0.620.68]) than STOPP in identifying PIMs.

In bivariate analysis, predictors of PIM identified by the Beers Criteria were the number of comorbidities of 1 , length of hospital stay of $\geq 10$ days, and patient age of 60-74 years. Whereas predictors of PIM identified by the STOPP were patient age of 65-79 years and length of hospital stay of 1-4 days (TABLE 3).

In the logistic regression model, predictors of PIM identified by the Beers Criteria ( $R 2=0.05$,
Model $\left.\chi^{2}(8)=666, p<0.001\right)$ were the number of comorbidities of 1 (odds ratio $[\mathrm{OR}]=1.97,95 \%$ $\mathrm{CI}=1.00-3.89, \mathrm{p}=0.05)$, length of hospital stay of $\geq 10$ days $(\mathrm{OR}=0.183,95 \% \mathrm{CI}=0.009-3.54, \mathrm{p}=0.26)$, and patient age of $60-74$ years $(\mathrm{OR}=0.52,95 \% \mathrm{CI}=0.276$ $0.967, \mathrm{p}=0.04)$. Whereas predictors of PIM identified by the STOPP (R2=0.03, Model $\chi^{2}(8)=11141$, $\mathrm{p}<0.001)$ were patient age of $65-69$ years $(\mathrm{OR}=0.43$, $95 \% \mathrm{CI}=0.23-0.83, \mathrm{p}=0.01)$, patient age of $70-74$ years (OR=0.43, 95\% $\mathrm{CI}=0.21-0.87, \mathrm{p}=0.02)$, and length of hospital stay of $1-4$ days (OR=0.76, 95\% $\mathrm{Cl}=0.48-1.18, \mathrm{p}=0.22)$.

\section{DISCUSSION}

In India, the age of retirement and senior citizenship 
TABLE 2

Potentially inappropriate medication (PIM) and adverse drug reaction (ADR) identified by Beers Criteria and Screening Tool of Older Persons' Potentially Inappropriate Prescriptions (STOPP)

\begin{tabular}{|c|c|c|c|c|c|}
\hline \multicolumn{3}{|c|}{ Beers Criteria } & \multicolumn{3}{|c|}{ STOPP } \\
\hline Drug & $\begin{array}{l}\text { No. of PIMs } \\
\text { independent } \\
\text { of diagnosis }\end{array}$ & $\begin{array}{l}\text { No. of ADRs } \\
\text { independent of } \\
\text { diagnosis }\end{array}$ & Drug & $\begin{array}{l}\text { No. of PIMs } \\
\text { independent } \\
\text { of diagnosis }\end{array}$ & $\begin{array}{l}\text { No. of ADRs } \\
\text { independent of } \\
\text { diagnosis }\end{array}$ \\
\hline Chlorpheniramine maleate & 9 & 1 (dry mouth) & Chlorpheniramine maleate & 9 & 1 (dry mouth) \\
\hline Aspirin & 2 & 2 (gastrointestinal ulcer) & Aspirin & 2 & 2 (gastrointestinal ulcer) \\
\hline Chlordiazepoxide & 4 & - & Chlordiazepoxide & 4 & - \\
\hline Digoxin & 4 & - & Digoxin & 4 & - \\
\hline Promethazine & 22 & 1 (confusion) & Promethazine & 22 & 1 (confusion) \\
\hline Amitriptyline & 6 & $\begin{array}{l}4 \text { ( } 2 \text { confusion, } \\
2 \text { constipation) }\end{array}$ & Hydrocortisone & 8 & 2 (hyperglycaemia) \\
\hline Clonazepam & 1 & - & Prednisolone & 5 & - \\
\hline Amiodarone & 5 & - & Deflazacort & 4 & - \\
\hline Clonidine & 2 & - & - & - & - \\
\hline Dabigatran & 1 & - & - & - & - \\
\hline Spironolactone & 13 & 1 (hyperkalaemia) & - & - & - \\
\hline Hydroxyzine hydrochloride & 3 & 1 (constipation) & - & - & - \\
\hline Metoclopramide & 19 & - & - & - & - \\
\hline Prazosin & 4 & $\begin{array}{l}1 \text { (orthostatic } \\
\text { hypotension) }\end{array}$ & - & - & - \\
\hline Zolpidem & 10 & - & - & - & - \\
\hline Meperidine & 8 & - & - & - & - \\
\hline Glyburide & 2 & - & - & - & - \\
\hline Hyoscine butylbromide & 2 & - & - & - & - \\
\hline Drug & $\begin{array}{l}\text { No. of PIMs } \\
\text { dependent of } \\
\text { diagnosis }\end{array}$ & $\begin{array}{l}\text { No. of ADRs } \\
\text { dependent of } \\
\text { diagnosis }\end{array}$ & Drug & $\begin{array}{l}\text { No. of PIMs } \\
\text { dependent of } \\
\text { diagnosis }\end{array}$ & $\begin{array}{l}\text { No. of ADRs } \\
\text { dependent of } \\
\text { diagnosis }\end{array}$ \\
\hline Diclofenac & 8 & - & Diclofenac & 8 & - \\
\hline Diltiazem & 8 & - & Diltiazem & 8 & - \\
\hline Ranitidine & 1 & - & Clopidogrel & 7 & - \\
\hline Tramadol & 1 & - & Cilnidipine & 3 & - \\
\hline Lorazepam & 1 & - & Furosemide & 16 & - \\
\hline- & - & - & Sertraline & 4 & 1 (hyponatraemia) \\
\hline- & - & - & Amlodipine & 4 & \\
\hline
\end{tabular}

is 60 years ${ }^{13}$ and life expectancy is 66 years, compared with life expectancy of 79 years in the United States and 81 years in the United Kingdom. ${ }^{14}$ In our study, there were more male than female patients $(64.6 \%$ vs. $35.4 \%)$, which is consistent with one study, ${ }^{15}$ but is in contrast with another study reporting more female than male patients $(61.9 \%$ vs. $38.1 \%) .{ }^{10}$ In our patients, an average of 10 drugs were prescribed, which is more than that reported in other studies with an average of 5 and 9 drugs per prescription. ${ }^{3,15}$
Limiting the number of drugs per prescription is recommended because of the risk of drug-drug interaction, drug-food interaction, ADR, increased hospital cost, errors of prescribing, unwanted side effects, and prescribing and dispensing errors. Many elderly patients require polypharmacy for various comorbidities; this is of concern as the chance of drug interactions increases. ${ }^{16,17}$

In our study, the number of PIMs identified by 
TABLE 3

Predictors of potentially inappropriate medication identified by the Beers Criteria and Screening Tool of Older Persons' Potentially Inappropriate Prescriptions (STOPP)

\begin{tabular}{|c|c|c|c|c|}
\hline \multirow[t]{2}{*}{ Predictor } & \multicolumn{2}{|c|}{ Beers Criteria } & \multicolumn{2}{|c|}{ STOPP } \\
\hline & OR $(95 \% \mathrm{Cl})$ & $p$ Value & OR $(95 \% \mathrm{Cl})$ & $\mathrm{p}$ Value \\
\hline \multicolumn{5}{|l|}{ Sex } \\
\hline Male & $0.78(0.52-1.17)$ & 0.231 & $0.99(0.65-1.52)$ & 0.98 \\
\hline Female & 1 & - & 1 & - \\
\hline \multicolumn{5}{|l|}{ Age (years) } \\
\hline $60-64$ & $0.51(0.27-0.96)$ & 0.039 & $0.73(0.40-1.33)$ & 0.316 \\
\hline $65-69$ & $0.33(0.17-, 0.63)$ & 0.0009 & $0.43(0.22-0.82)$ & 0.011 \\
\hline $70-74$ & $0.43(0.22-0.87)$ & 0.019 & $0.42(0.21-0.86)$ & 0.018 \\
\hline $75-79$ & $0.49(0.23-1.05)$ & 0.069 & $0.44(0.20-0.94)$ & 0.03 \\
\hline$\geq 80$ & 1 & - & 1 & - \\
\hline \multicolumn{5}{|c|}{ No. of comorbidities } \\
\hline 1 & $1.97(1.0-3.88)$ & 0.049 & 1.39 (0.69-2.81) & 0.34 \\
\hline 2 & $0.83(0.40-1.71)$ & 0.621 & $0.86(0.40-1.85)$ & 0.7 \\
\hline 3 & $1.43(0.67-3.05)$ & 0.353 & $1.54(0.70-3.38)$ & 0.27 \\
\hline$\geq 4$ & 1 & - & 1 & - \\
\hline \multicolumn{5}{|c|}{ No. of medications } \\
\hline $1-4$ & - & - & & - \\
\hline $5-9$ & - & - & & - \\
\hline $10-14$ & $1.13(0.71-1.80)$ & 0.584 & $1.06(0.65-1.71)$ & 0.81 \\
\hline 15 & 1 & - & 1 & - \\
\hline \multicolumn{5}{|c|}{ Length of hospital stay (days) } \\
\hline $1-4$ & $0.97(0.63-1.51)$ & 0.919 & $0.75(0.48-1.18)$ & 0.22 \\
\hline $5-9$ & 1 & - & 1 & - \\
\hline $10-14$ & $0.18(0.009-3.54)$ & 0.261 & - & - \\
\hline$\geq 15$ & $0.16(0.008-2.89)$ & 0.215 & - & - \\
\hline
\end{tabular}

the Beers Criteria was higher than that identified by STOPP (136 vs. 108). In one study STOPP identified more patients with PIM than the Beers Criteria (48\% vs. $25 \%),{ }^{3}$ but in another study STOPP identified fewer patients with PIM than the Beers Criteria (25\% vs. $35 \%) .{ }^{18}$ Disease characteristics and increased use of some drugs could be a reason for the difference. In our study, the Beers Criteria was more sensitive but less specific than STOPP in identifying PIM. The Beers Criteria identified more PIMs independent of disease (117 vs. 58) and fewer PIMs dependent of disease (19 vs. 50$)$ and more ADRs (11 vs. 7) compared with STOPP.

\section{CONCLUSION}

The Beers Criteria was more sensitive but less specific than STOPP in identifying PIMs. The prevalence of PIMs was high among elderly patients in our geriatric medicine ward. The use of the Beers Criteria or STOPP may help reduce PIM and ADR.

\section{ACKNOWLEDGMENTS}

The authors would like to thank the physicians, pharmacists, and nursing staff of Bangalore Baptist Hospital and teaching staff of the Pharmacy Practice Department of Karnataka Collage of Pharmacy and Dr. Carolin Elizabeth George and Dr. Tatarao M of Bangalore Baptist Hospital.

\section{REFERENCES}

1. Fialova D, Topinkova E, Gambassi G, Finne-Soveri H, Jónsson PV, Carpenter I et al. Potentially inappropriate medication use among 
elderly home care patients in Europe. JAMA 2005;293:1348-58.

2. Mangoni AA, Jackson SH. Age-related changes in pharmacokinetics and pharmacodynamics: basic principles and practical applications. Br J Clin Pharmacol 2004;57:6-14.

3. Ubeda A, Ferrandiz L, Maicas N, Gomez C, Bonet M, Peris JE. Potentially inappropriate prescribing in institutionalised older patients in Spain: the STOPP-START criteria compared with the Beers criteria. Pharm Pract (Granada) 2012;10:83-91.

4. Verdoorn S, Kwint HF, Faber A, Gussekloo J, Bouvy ML. Majority of drug-related problems identified during medication review are not associated with STOPP/START criteria. Eur J Clin Pharmacol 2015;71:1255-62.

5. Brown JD, Hutchison LC, Li C, Painter JT, Martin BC. Predictive validity of the Beers and Screening Tool of Older Persons' Potentially Inappropriate Prescriptions (STOPP) Criteria to detect adverse drug events, hospitalizations, and emergency department visits in the United States. J Am Geriatr Soc 2016;64:22-30.

6. Hamano J, Ozone S, Tokuda Y. A comparison of estimated drug costs of potentially inappropriate medications between older patients receiving nurse home visit services and patients receiving pharmacist home visit services: a cross-sectional and propensity score analysis. BMC Health Serv Res 2015;15:73.

7. Gallagher P, O'Mahony D. STOPP (Screening Tool of Older Persons' potentially inappropriate Prescriptions): application to acutely ill elderly patients and comparison with Beers' criteria. Age Ageing 2008;37:673-9.

8. Gallagher P, Ryan C, Byrne S, Kennedy J, O'Mahony D. STOPP (Screening Tool of Older Person's Prescriptions) and START (Screening Tool to Alert doctors to Right Treatment). Consensus validation. Int J Clin Pharmacol Ther 2008;46:72-83.

9. Momin TG, Pandya RN, Rana DA, Patel VJ. Use of potentially inappropriate medications in hospitalized elderly at a teaching hospital: a comparison between Beers 2003 and 2012 criteria. Indian J Pharmacol 2013;45:603-7.

10. Oliveira MG, Amorim WW, de Jesus SR, Heine JM, Coqueiro HL, Passos LC. A comparison of the Beers and STOPP criteria for identifying the use of potentially inappropriate medications among elderly patients in primary care. J Eval Clin Pract 2015;21:320-5.

11. Naranjo CA, Busto U, Sellers EM, Sandor P, Ruiz I, Roberts EA, et al. A method for estimating the probability of adverse drug reactions. Clin Pharmacol Ther 1981;30:239-45.

12. Parthasarathi G, Nyfort-Hansen K, Nahata MC. A text book of clinical pharmacy practice: essential concepts and skills. 2nd ed. Hyderabad: Orient Longman; 2004.

13. Maintenance and Welfare of Parents and Senior Citizens Act, 2007. Ministry of Social Justice and Empowerment. Government of India. Available from: http://socialjustice.nic.in/oldageact.php. Accessed 11 September 2016.

14. World Health Statistics 2005. Available from: http://apps.who.int/ iris/bitstream/10665/170250/1/9789240694439_eng.pdf?ua=1. Accessed 11 September 2016.

15. Vishwas HN, Harugeri A, Parthasarathi G, Ramesh M. Potentially inappropriate medication use in Indian elderly: comparison of Beers' criteria and Screening Tool of lder Persons' potentially inappropriate Prescriptions. Geriatr Gerontol Int 2012;12:506-14.

16. Linjakumpu T, Hartikainen S, Klaukka T, Veijola J, Kivela SL, Isoaho R. Use of medications and polypharmacy are increasing among the elderly. J Clin Epidemiol 2002;55:809-17.

17. FlahertyJH, Perry HM 3rd, Lynchard GS, MorleyJE. Polypharmacy and hospitalization among older home care patients. J Gerontol A Biol Sci Med Sci 2000;55:M554-9.

18. Gallagher P, Barry $\mathrm{P}, \mathrm{O}^{\prime}$ Mahony D. Inappropriate prescribing in the elderly. J Clin Pharm Ther 2007;32:113-21. 